\title{
EXPERIMENTAL AND THEORETICAL DETERMINATION OF SPECIFIC HEATS, PHASE TRANSFORMATIONS TEMPERATURES AND ENTHALPY OF FE-C-CR-NI ALLOWS
}

\author{
${ }^{1}$ Svetlana SOROKINA, 'Bedřich SMETANA, 'L'ubomíra DROZDOVÁ, 'Monika KAWULOKOVÁ, \\ 'Simona ZLÁ
}

${ }^{1}$ Faculty of materials science and technology, VŠB-Technical University of Ostrava, 17. listopadu 15, Ostrava-Poruba, 708 00, Czech Republic, EU, svetlana.sorokina.st@vsb.cz

https://doi.org/10.37904/metal.2020.3530

\begin{abstract}
Knowledge of thermodynamical and thermophysical properties of materials plays an important role for many industrial applications. The paper is dedicated to the study of three model alloys based on Fe-C-Cr-Ni. The studied alloys contained carbon in a range of $0.33-0.36 \mathrm{wt} \%$, chromium $1.08-4.70 \mathrm{wt} \%$ and nickel $1.04-$ $4.96 \mathrm{wt} \%$. Thermophysical and thermodynamical properties depending on the composition of alloys such as specific heats, phase transformations temperatures and enthalpy were studied in low and high temperature areas. Experimental data were obtained using following devices: Setaram Sensys Evo and Setaram MHTC Line 96 with 3D DSC sensors. Specific heats were obtained using the continuous method. All measurements were performed in a helium atmosphere. The same properties were calculated using SW Thermo-Calc, then were compared and discussed with experimental data.
\end{abstract}

Keywords: Fe-C-Cr-Ni alloys, specific heats, phase transformations temperatures, enthalpy, low and high temperature areas

\section{INTRODUCTION}

Studying of thermodynamical and thermophysical properties of systems based on Fe is very important, because these materials are used almost in all sectors of modern production. These properties are needed for understanding the basis of fundamental behavior of materials depending on their composition and various experimental conditions [5]. Specific heats, phase transformations temperatures, enthalpy, entropy, Gibbs energy and other properties are the main material data for the thermodynamic and thermophysical description of materials [1-2,6]. Many of properties are often studied using thermal analysis methods and calorimetry, which denote a variety of measuring methods.

Performed study presents specific heats, temperatures of transformation of $\alpha \rightarrow \gamma$, solidus and liquidus and enthalpy of laboratory prepared Fe-C-Cr-Ni alloys obtained by Differential Scanning Calorimetry (DSC). These data were discussed and compared with results calculated using one of the most powerful software package for thermodynamic calculations Thermo-Calc.

\section{EXPERIMENT}

\subsection{Sample characterization}

The studied alloys contained carbon in a range of $0.33-0.36 \mathrm{wt} \%$, chromium $1.08-4.70 \mathrm{wt} \%$ and nickel 1.04 $-4.96 \mathrm{wt} \%$. The samples for a thermal analysis were in cylindrical forms with following characteristics: diameter was $5 \mathrm{~mm}$ and height $8 \mathrm{~mm}$, mass was approximately $1250 \mathrm{mg}$. The samples were polished and then cleaned in acetone using ultrasound. 
The chemical composition of three model alloys based on Fe-C-Cr-Ni is presented in Table 1.

Table 1 Chemical composition of alloys (wt\%)

\begin{tabular}{|c|c|c|c|c|c|c|c|}
\hline Alloy & C & Cr & Ni & Mn & Cu & Co & W \\
\hline A & 0.360 & 1.080 & 1.040 & 0.030 & 0.012 & - & - \\
\hline B & 0.340 & 2.950 & 3.040 & 0.027 & 0.014 & 0.013 & 0.030 \\
\hline C & 0.360 & 4.700 & 4.960 & 0.034 & 0.014 & 0.015 & - \\
\hline
\end{tabular}

Minor elements content in the studied alloys were in the following intervals: $\mathrm{O}$ (up to $0.004 \mathrm{wt} \%$ ),

(up to $0.001 \mathrm{wt} \%$ ), Mo (up to $0.001 \mathrm{wt} \%$ ), N (up to $0.005 \mathrm{wt} \%$ ), B (up to $0.002 \mathrm{wt} \%$ ).

\subsection{DSC - Differential scanning calorimetry and experimental conditions}

Experimental data of thermodynamical and thermophysical properties depending on the composition of alloys were obtained using Setaram Sensys Evo and Setaram MHTC Line 96 with a 3D DSC sensor. The measurements were carried out in a low and high temperature areas as well in the atmosphere of helium with purity at least $6 \mathrm{~N}$ to protect the samples against oxidation. Temperature calibration was done using Pd and $\mathrm{Au}$ for all samples. An empty corundum crucible was as a reference sample. The heating rate was $5{ }^{\circ} \mathrm{C} / \mathrm{min}$. Specific heats (apparent heat capacities) were obtained using the continuous method (continuous linear heating or cooling in the controlled atmosphere) [3]. The heat flux of studied samples was measured relative to the heat flux of the reference sample. Enthalpic calibration was performed using Pt (3N5) for all alloys.

\section{THEORETICAL BACKGROUND}

Theoretical values of specific heats, phase transformations temperatures and enthalpy were calculated by use of thermodynamic SW Thermo-Calc, which has a high-quality database for various materials including Febased alloys as well. Elements such as O, P, S, N, B and diamond and graphite phases were not included for calculations. Used SW does not calculate specific heats directly; specific heats were calculated using suitable equation based on the next relation (equation 1) [4]:

$\mathrm{Cp}=\mathrm{dH} / \mathrm{dT} \quad(\mathrm{J} / \mathrm{K} \cdot \mathrm{g})$

where $C p$ is specific heat $(\mathrm{J} / \mathrm{K} \cdot \mathrm{g}), \mathrm{H}$ is enthalpy $(\mathrm{J})$ and $T$ is temperature $(\mathrm{K})$.

As for phase transition temperatures, temperatures of transformation of $\alpha \rightarrow \gamma$, solidus and liquidus temperatures were obtained using calculated phase diagrams.

\section{RESULTS AND DISCUSSION}

\subsection{Specific heats}

The specific heats of alloys $A, B$ and $C$ were studied in the temperature intervals from $30{ }^{\circ} \mathrm{C}$ to $1580{ }^{\circ} \mathrm{C}$. Theoretical values of the heat capacities were obtained by SW Thermo-Calc and compared with measured experimental values. Obtained experimental and theoretical values of the specific heats are presented in the Figures $1-3$.

\section{Alloy A}

From the dependence of specific heats on temperature (Figure 1) can be seen, that obtained experimental and theoretical data have the same trend in the temperature intervals: $30^{\circ} \mathrm{C}$ to $717^{\circ} \mathrm{C}, 799^{\circ} \mathrm{C}$ to $1432^{\circ} \mathrm{C}$ and 1522 to $1580^{\circ} \mathrm{C}$. In these temperature intervals experimental values of specific heats are $0.37-1.06 \mathrm{~J} / \mathrm{K} \cdot \mathrm{g}$ 
and theoretical values of specific heats are $0.45-0.96 \mathrm{~J} / \mathrm{K} \cdot \mathrm{g}$. In the region of phase transformation $\alpha \rightarrow \gamma$ the highest experimental value of the specific heat is $4.88 \mathrm{~J} / \mathrm{K} \cdot \mathrm{g}$ and the highest theoretical value of the specific heat is $6.44 \mathrm{~J} / \mathrm{K} \cdot \mathrm{g}$, difference between these values is $1.56 \mathrm{~J} / \mathrm{K} \cdot \mathrm{g}$. In the melting range the highest experimental value of the specific heat is $10.92 \mathrm{~J} / \mathrm{K} \cdot \mathrm{g}$ and the highest theoretical value of the specific heat is $12.42 \mathrm{~J} / \mathrm{K} \cdot \mathrm{g}$, difference between these values is $1.50 \mathrm{~J} / \mathrm{K} \cdot \mathrm{g}$.

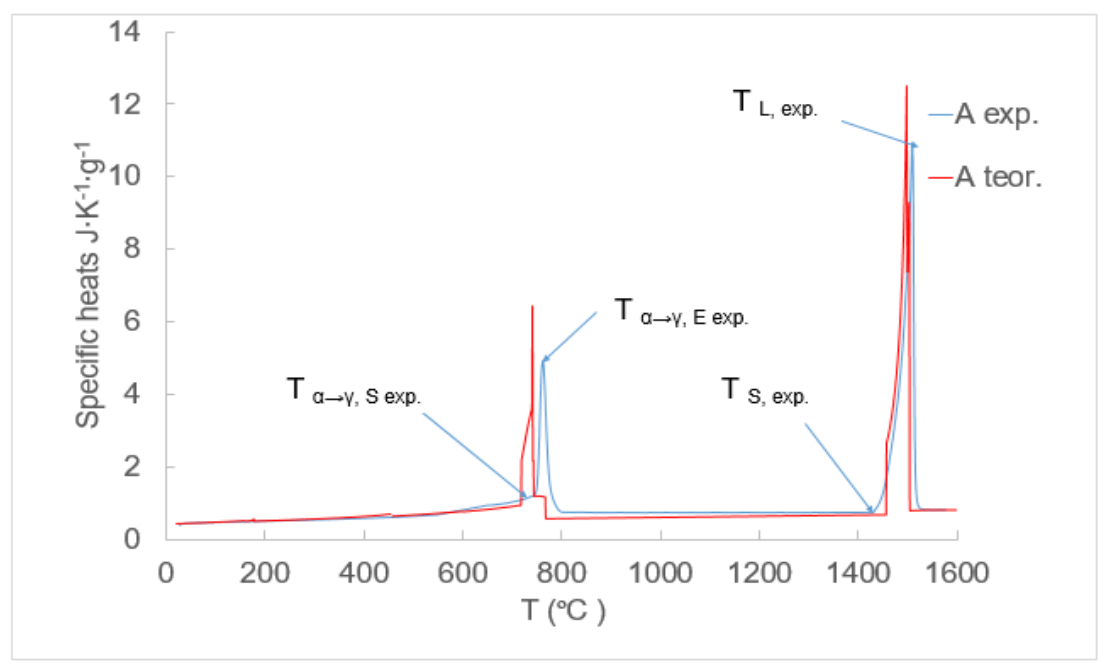

Figure 1 Comparison of experimental and theoretical heat capacities of alloy $\mathrm{A}$

\section{Alloy B}

From the dependence of specific heats on temperature (Figure 2) it is clear, that obtained experimental and theoretical data have the same trend in the temperature intervals: $30^{\circ} \mathrm{C}$ to $669{ }^{\circ} \mathrm{C}, 786{ }^{\circ} \mathrm{C}$ to $1420{ }^{\circ} \mathrm{C}$ and 1517 to $1580^{\circ} \mathrm{C}$. In these temperature intervals experimental values of specific heats are $0.36-0.77 \mathrm{~J} / \mathrm{K} \cdot \mathrm{g}$ and theoretical values of specific heats are $0.45-0.91 \mathrm{~J} \mathrm{~K} \cdot \mathrm{g}$. In the range of phase transformation $\alpha \rightarrow \gamma$ the highest experimental value of the specific heat is $2.85 \mathrm{~J} / \mathrm{K} \cdot \mathrm{g}$ and the highest theoretical value of the specific heat is $2.73 \mathrm{~J} / \mathrm{K} \cdot \mathrm{g}$, difference between these values is $0.12 \mathrm{~J} / \mathrm{K} \cdot \mathrm{g}$. In the melting range the highest experimental value of the specific heat is $11.29 \mathrm{~J} / \mathrm{K} \cdot \mathrm{g}$ and the highest theoretical value of the specific heat is $16.13 \mathrm{~J} / \mathrm{K} \cdot \mathrm{g}$, difference between these values is $4.84 \mathrm{~J} / \mathrm{K} \cdot \mathrm{g}$.

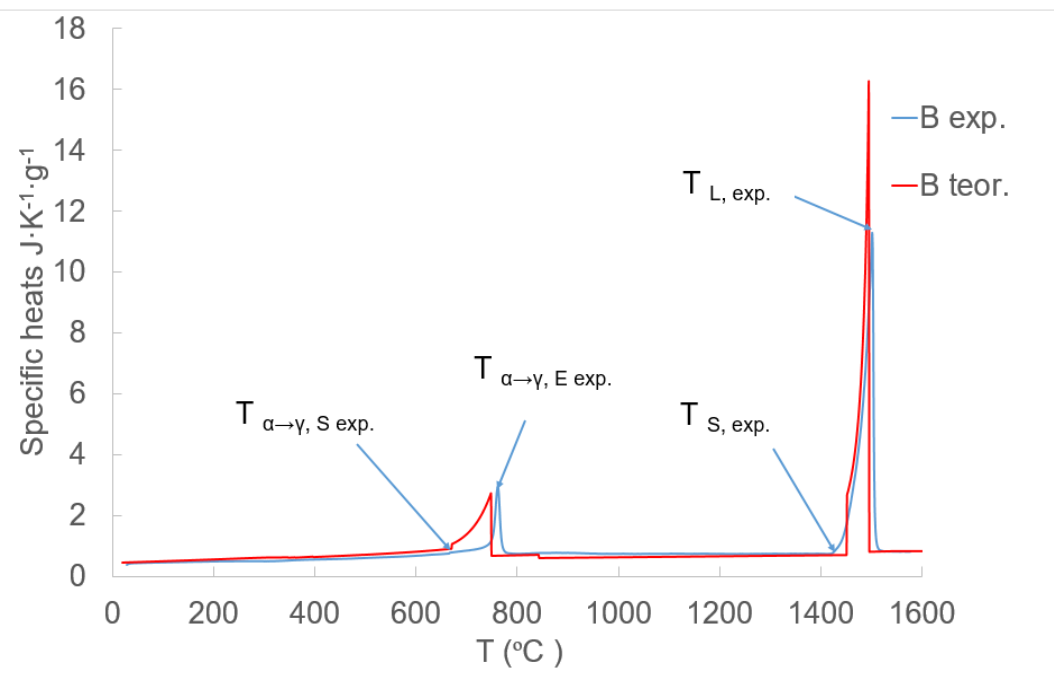

Figure 2 Comparison of experimental and theoretical heat capacities of alloy $\mathrm{B}$ 


\section{Alloy C}

From the dependence of specific heats on temperature (Figure 3 ) it is visible, that obtained experimental and theoretical data have the same trend in the temperature intervals: $30^{\circ} \mathrm{C}$ to $620^{\circ} \mathrm{C}, 793^{\circ} \mathrm{C}$ to $1419{ }^{\circ} \mathrm{C}$ and 1509 to $1580^{\circ} \mathrm{C}$. In these temperature intervals experimental values of specific heats are $0.39-0.78 \mathrm{~J} / \mathrm{K} \cdot \mathrm{g}$ and theoretical values of specific heats are $0.46-0.93 \mathrm{~J} / \mathrm{K} \cdot \mathrm{g}$. In the region of the phase transformation $\alpha \rightarrow \gamma$ the highest experimental value of the specific heat is $0.98 \mathrm{~J} / \mathrm{K} \cdot \mathrm{g}$ and the highest theoretical value of the specific heat is $2.11 \mathrm{~J} / \mathrm{K} \cdot \mathrm{g}$, difference between these values is $1.13 \mathrm{~J} / \mathrm{K} \cdot \mathrm{g}$. In the melting range the highest experimental value of the specific heat is $10.41 \mathrm{~J} / \mathrm{K} \cdot \mathrm{g}$ and the highest theoretical value of the specific heat is $13.56 \mathrm{~J} / \mathrm{K} \cdot \mathrm{g}$, difference between these values is $3.15 \mathrm{~J} / \mathrm{K} \cdot \mathrm{g}$.

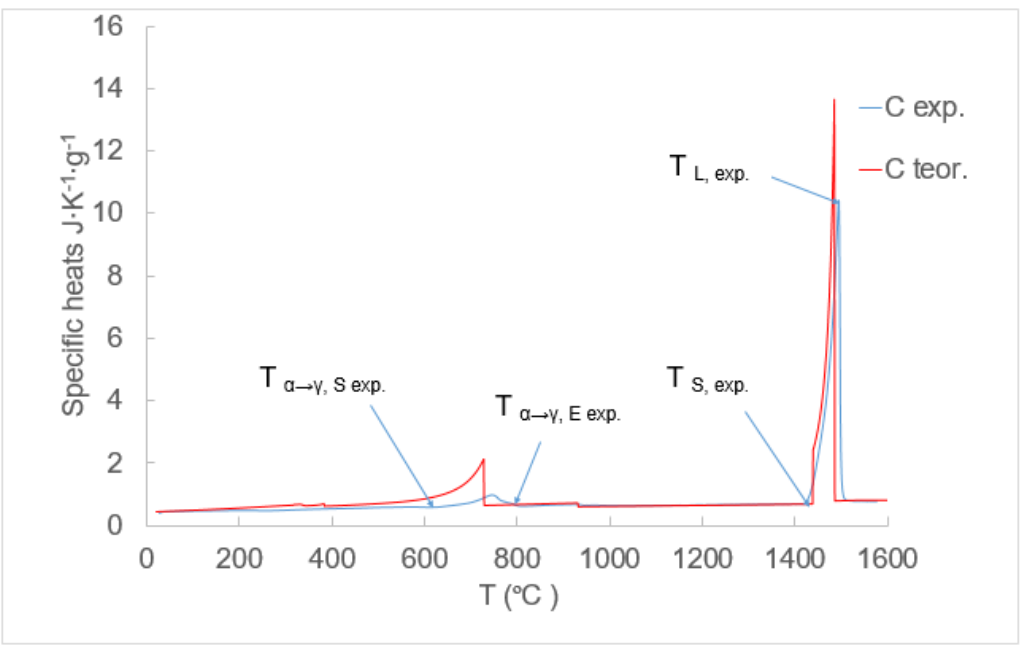

Figure 3 Comparison of experimental and theoretical heat capacities of alloy $\mathrm{C}$

In accordance with received data of dependence of specific heats on temperature and content of studied alloys, we can find out next regularity: the lowest values of specific heats were obtained for alloy with the highest content of nickel and chromium in the phases of liquidus and solidus.

\subsection{Phase transformations temperatures}

Experimental and theoretical values of phase transformations temperatures of studied alloys are in Table 2.

As for phase transformations temperatures, experimental values were detected from DSC curves and are presented and marked in the Figures $\mathbf{1}-\mathbf{3}$ and presented in Table 2. Theoretical values of phase transformations temperatures were obtained by SW Thermo-Calc (temperatures are presented and marked in the Figures $1-3$ and Table 2 as well) and compared with experimental values. The start and end of $\alpha \rightarrow \gamma$ transformation are marked as $T_{\alpha \rightarrow \gamma, S}$ and $T_{\alpha \rightarrow \gamma, E}$, the temperatures of liquidus and solidus are marked as $T_{L}$ and $T_{S}$. $T_{\alpha \rightarrow \gamma, S}, T_{\alpha \rightarrow \gamma, E}$ and $T_{S}$ show the highest differences between teoretical and experimental values, because it is difficult to determine it by thermal analysis methods.

Table 2 Experimental and theoretical values of phase transformations temperatures of studied alloys

\begin{tabular}{|c|c|c|c|c|c|c|}
\hline & alloy & A & alloy & B & alloy & C \\
\hline Temperature & DSC & $\mathrm{TC}$ & DSC & $\mathrm{TC}$ & DSC & $\mathrm{TC}$ \\
\hline$T_{\alpha \rightarrow \gamma, S}$ & 748 & 717 & 750 & 670 & 620 & - \\
\hline$T \alpha_{\rightarrow \gamma, E}$ & 791 & 766 & 774 & 748 & 802 & 727 \\
\hline$T_{s}$ & 1434 & 1456 & 1422 & 1447 & 1427 & 1437 \\
\hline $\mathrm{T}_{\mathrm{L}}$ & 1498 & 1502 & 1492 & 1493 & 1485 & 1485 \\
\hline
\end{tabular}


From Table 2 it is evident, that with increasing content of nickel and chromium in studied alloys the temperature of liquidus decreases correspondingly, differences between experimental and theoretical values were minimal. As to start and end of $\alpha \rightarrow \gamma$ and temperature of solidus, there is no ambiguous trend. Alloy $B$ has the highest $T_{\alpha \rightarrow \gamma, S}$ and alloy $C$ has the lowest $T$ a $\rightarrow \gamma, S$. Alloy $C$ has the highest $T_{\alpha \rightarrow \gamma, E}$ and alloy $B$ has the lowest $T_{\alpha \rightarrow \gamma, E}$. Alloy $A$ has the highest $T s$ and alloy $C$ has the lowest $T s$.

\subsection{Dependence of enthalpy on temperature}

Experimental values of enthalpy are presented in Figure 4. Obtained experimental and theoretical data have the same trend in studied temperature intervals: $30^{\circ} \mathrm{C}$ to $1580^{\circ} \mathrm{C}$, from Figure 4 it is clear, that with increasing of temperature enthalpy increases as well. The highest standard deviations are in the range of phase transformations. The highest value of standard deviation for alloy $C$ is $70.83 \mathrm{~J} / \mathrm{g}$ and for alloy $A$ is $33.81 \mathrm{~J} / \mathrm{g}$ in the melting range, for alloy $B$ is $60.32 \mathrm{~J} / \mathrm{g}$ in the range of phase transformations $\alpha \rightarrow \gamma$.

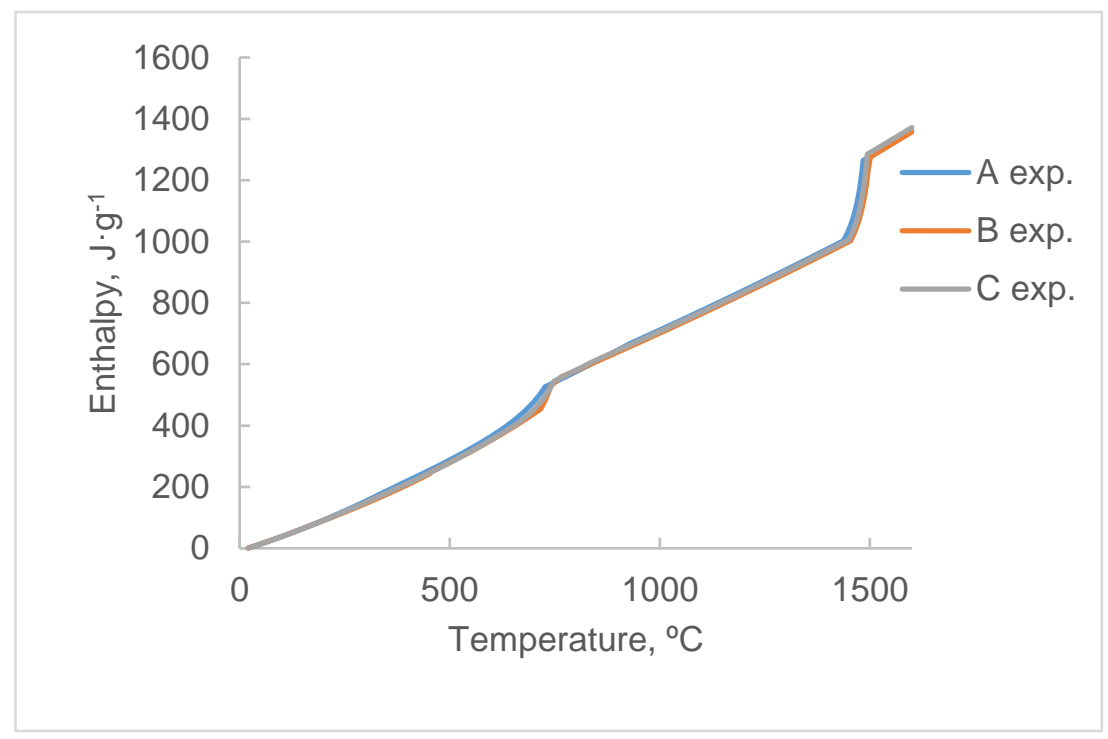

Figure 4 Dependence of experimental values of enthalpy on temperature

\section{CONCLUSION}

In the presented work specific heats, phase transformations temperatures and enthalpy of three alloys based on iron, nickel, carbon and chromium were studied in low and high temperature areas using DSC and SW Thermo-Calc. The specific heats decrease with increasing content of nickel and chromium in the area outside of phase transformations. The highest differences between theoretical and experimental phase transformations temperatures were in case of $T_{\alpha \rightarrow \gamma, S}$ (diference up to $80^{\circ} \mathrm{C}$ ), the best match was obtained for $T\left\llcorner\right.$ (difference up to $4^{\circ} \mathrm{C}$ ). Except specific heats and phase transformations temperatures, dependence of enthalpy on temperature was experimentally determined. New original experimental data were obtained for studies alloys.

\section{ACKNOWLEDGEMENTS}

This paper was supported in the frame of GAČR reg. no. 17-18668S project solution, project No. CZ.02.1.01/0.0/0.0/17_049/0008399 Call 02_17_049 Long-Term Intersectoral Cooperation for ITI, 


\section{REFERENCES}

[1] KOMOROVÁ, L., IMRIŠ, I. Thermodynamics in metallurgy. Bratislava: Alfa, 1990.

[2] SMETANA B., ŽALUDOVÁ, M., TKADLEČKOVÁ, M., DOBROVSKÁ, J., ZLÁ, S., GRYC, K., KLUS, P., MICHALEK, K., MACHOVČÁK, P., ŘEHÁČKOVÁ, L. Experimental verification of hematite ingot mould heat capacity and its direct utilization in simulation of casting process. Journal of Thermal Analysis and Calorimetry. 2013, vol. 112, no. 1, pp. 473-480.

[3] GALLAGHER, P.K. Handbook of Thermal Analysis and Calorimetry: Principles and Practice. London: Elsevier; 2003.

[4] Coll. of authors. TG and MHTC manual version. France: Setaram; 2009.

[5] KJELLQVIST, L., SELLEBY, M. Thermodynamic assessment of the Fe-Mn-O system. Journal of phase equilibria and diffusion. 2010, vol. 31, no. 2, pp.113-134.

[6] DING, Y., LIU, Y., YAN, Y., SU, X. Thermodynamic analysis and experimental study on the phase equilibria in FeMn-Cr-O system. Journal of Alloys and Compounds. 2018, vol. 130, no. 1, pp. 1-8. 